\title{
Increasing The Efficiency Of The Photovoltaic (PV) Array Utilization With Experimental Results
}

\author{
F.Z Zerhouni ${ }^{1}$, M.H Zerhouni ${ }^{2}$, M. Zegrar ${ }^{3}$, M.T Benmessaoud ${ }^{4}$, A. Boudghene Stambouli ${ }^{5}$ \\ ${ }^{1-5}$ Electrical Engineering Faculty \\ Electronics Department \\ University of Sciences and Technology Mohamed Boudiaf of Oran USTOMB \\ BP 1505 El M'naouer 31000 Oran, (Algeria) \\ Phone/Fax number: 04156 0329, e-mail: zerhouni_fz@yahoo.fr ${ }^{1}$ \\ stambouli@ssb-foundation.com ${ }^{5}$
}

\begin{abstract}
The reason for this paper is to give methods verified experimentally, to use in an efficient manner, a green system using photovoltaic energy. This study concerns optimization of photovoltaic system operation, in real time. Tracking maximum power method has been verified experimentally. Another technique for optimum switching of photovoltaic (PV) modules with electrical array reconfiguration is proposed, whatever are conditions (insulation, temperature, load). A microcontroller is used as support of the electronic control and practical tests are presented.
\end{abstract}

\section{Key words}

PV panel, tracking, insulation, temperature, reconfiguration.

\section{Introduction}

Solar energy is one of the most promising renewable sources. The paper is approaching a theme: renewable photovoltaic source for optimum energy production. The purpose of the work is to optimize the system's operation. The main reason for this paper is to give methods verified experimentally to supply in an efficient manner a green system using photovoltaic energy.

\section{Model Of Pv Array}

Photovoltaic (PV) cells convert photon power [1]-[2] into electrical power which is delivered to load (Figure 1).

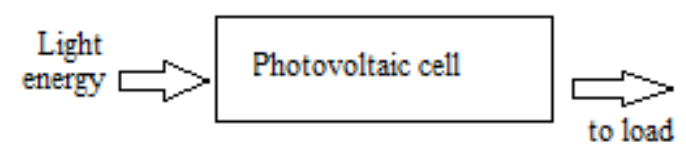

Fig. 1. Photovoltaic cell conversion

The power produced by a single PV cell is not enough for general use. Model of PV Cell selected is a single diode.
The equivalent circuit shows in Figure 2 is formed by a current source in parallel with a diode and includes two resistors [1-3].

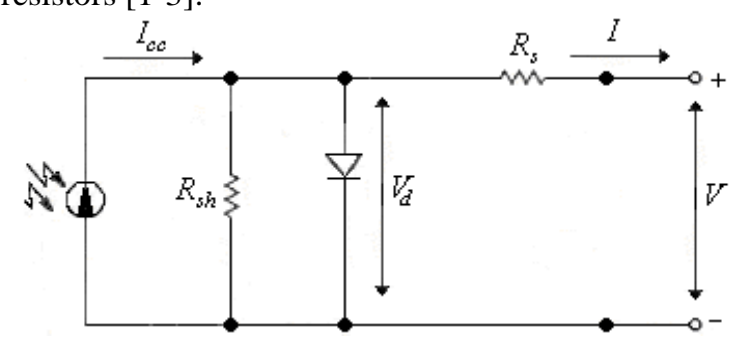

Fig. 2. Photovoltaic cell equivalent circuit

$$
I=I_{c c}-I_{o}\left[\exp \frac{\left(V+R_{S} I\right)}{A \cdot U_{T}}-1\right]-\left(\frac{V+R_{S} I}{R_{s h}}\right)
$$

Where

I is the output current.

$\mathrm{V}$ is the output voltage.

Rs is serial resistance which takes into account contact's and connection's resistances.

Rsh is parallel resistance which represents the leakage current at the junction.

$\mathrm{U}_{\mathrm{T}}$ : thermal potential.

Iph is the photocurrent source equal to the short-circuit current Icc.

Io is the saturation current of a solar cell.

$\mathrm{A}$ is the ideality factor for a $\mathrm{p}-\mathrm{n}$ junction.

At the open-circuit point on the current-voltage I-V curve, $\mathrm{V}=\mathrm{Voc}$ and $\mathrm{I}=0$.

At the short-circuit point on the I-V curve, $\mathrm{I}=\mathrm{Icc}$ and $\mathrm{V}$ $=0$.

At the maximum-power point on the $\mathrm{I}-\mathrm{V}$ curve, $\mathrm{I}=\mathrm{Iopt}$ and $\mathrm{V}=$ Vopt.

In our case, 36 polycristallin PV cells Kyocera LA 361 K51 are connected in series to form a PV module. The PV cell model can be used for PV module. Data sheet information are values in standard conditions of measurement : Voc, Icc, Popt (optimal power),Vopt,Iopt. Electrical parametersl for PV module used are: 
Voc $=21.2 \mathrm{~V}$, Icc $=3.25 \mathrm{~A}, \mathrm{Vopt}=16.9 \mathrm{~V}$, Iopt $=3.02 \mathrm{~A}$, Rs $=0.4 \Omega$.

\section{Photovoltaic Array}

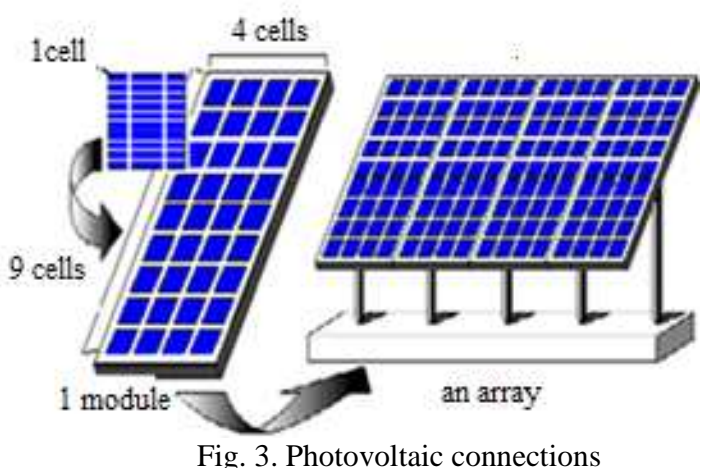

An array (Figure 3) is a structure that consists of a number of PV modules, mounted on the same plane with electrical connections to provide enough electrical power. To increase the voltage, modules are connected in series and to increase the current, they are connected in parallel [2]. $\mathrm{Np}$ represents strings in parallel connections. Each string is Ns modules connected in series. The mathematical equation of generalized model for photovoltaic array (PVA) can be described as[2]:

$$
I=N_{p} I_{c c}-N_{p} I_{o}\left[\exp \frac{\left(V+R_{s} \frac{N_{s}}{N_{p}} I\right)}{A \cdot U_{T} N_{s}}-1\right]-\left(\frac{V+R_{s} \frac{N_{s}}{N_{p}} I}{\frac{N_{p}}{N_{s}} R_{s h}}\right)
$$

If Rsh is neglected:

$$
I=N_{p} I_{c c}-N_{p} I_{o}\left[\exp \frac{\left(V+R_{s} \frac{N_{s}}{N_{p}} I\right)}{A \cdot U_{T} N_{s}}-1\right]
$$

\section{PV Module Modeling}

Figure (4) illustrates the PVA characteristics curves obtained I-V: current-voltage, at different insulations Es at temperature $\mathrm{T}=25^{\circ} \mathrm{C}$ for one PV module [2].

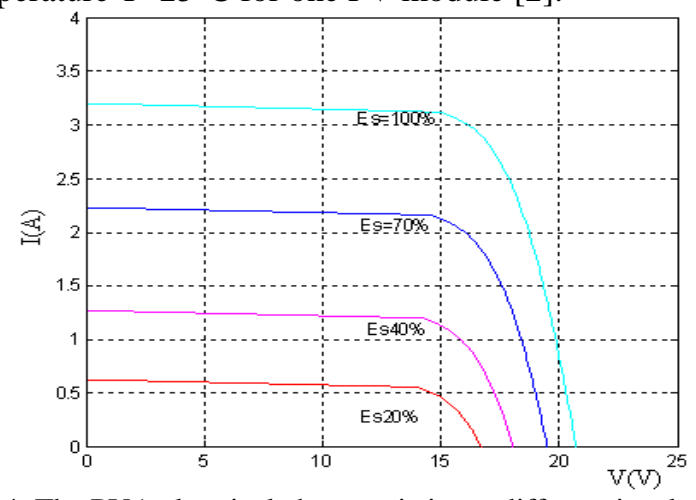

Fig. 4. The PVA electrical characteristics at different insulations, $\mathrm{T}=25^{\circ} \mathrm{C}$

Figure (5) illustrates the PVA characteristics curves obtained I-V: current-voltage, at different temperatures at
Es constant $\left(\mathrm{Es}=1 \mathrm{~kW} / \mathrm{m}^{2}\right.$ corresponding to $\left.\mathrm{Es}=100 \%\right)$ for one PV module [2].

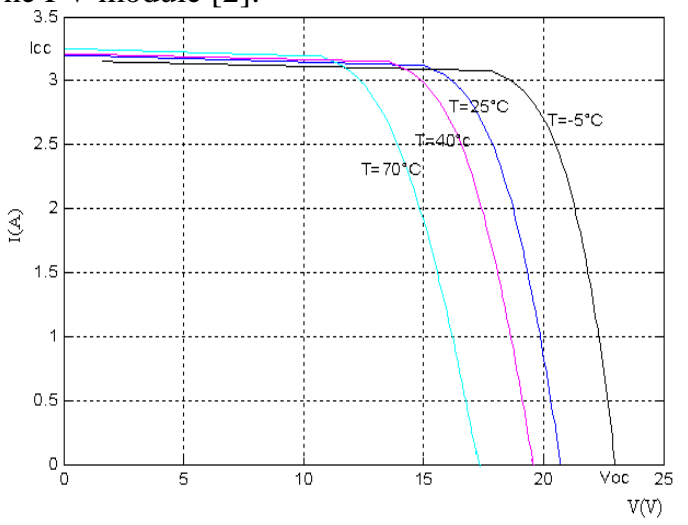

Fig. 5. The PVA electrical characteristics $\mathrm{I}-\mathrm{V}$ at different temperatures , Es $=100 \%$

\section{Photovoltaic Array Maximum Power}

It is observed that the solar array output characteristics are nonlinear and affected by the insulation, temperature [2]. The relationship of power-voltage $(\mathrm{P}-\mathrm{V})$ for a photovoltaic module is

$$
P=V . . I=-R_{s} \cdot I^{2}+A . U_{T} I . \operatorname{Ln}\left(\frac{I_{c c}-I+I_{o}}{I_{o}}\right)
$$

$$
\frac{d P}{d I}=-2 \cdot R_{s} \cdot I+A \cdot U_{T} \cdot \operatorname{Ln}\left(\frac{I_{c c}-I+I_{o}}{I_{o}}\right)-\frac{I \cdot A \cdot U_{T}}{I_{c c}-I+I_{o}}=0
$$

$$
I_{c c}=I_{o p t}+I_{o}\left[\exp \left(\frac{\left(2 . I_{o p t} \cdot R_{s}\right)}{A \cdot U_{T}}+\frac{I_{o p t}}{I_{c c}-I_{o p t}+I_{o}}\right)-1\right]
$$

Eq. 6 can be solved using for example Newton Raphstons method. The current Iopt is obtained using Eq 6 and voltage Vopt is obtained using Eq. 1.

Each curve I-V, for specific conditions has only one maximum power point (MPP) of coordinates (Iopt-Vopt), which is the optimal operating point for solar array efficient use. As shown in Figure 6-a, the maximum electric power increases with the irradiance Es. To show the effect of temperature on the performance of a module, the irradiance is kept fixed at $1000 \mathrm{~W} / \mathrm{m}^{2}$ corresponding to Es $=100 \%$ and the values of temperatures are changed to different values (Figure 6-b). The maximum electric power strongly decreases with temperature (Figure 6-b) [2]. Iopt variation versus $\mathrm{T}$ and Es is shown in Figure 6-c. 


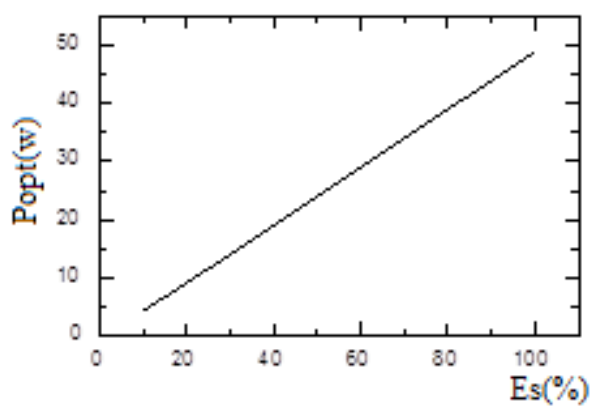

a- under varied solar irradiance, $\mathrm{T}=25^{\circ} \mathrm{C}$

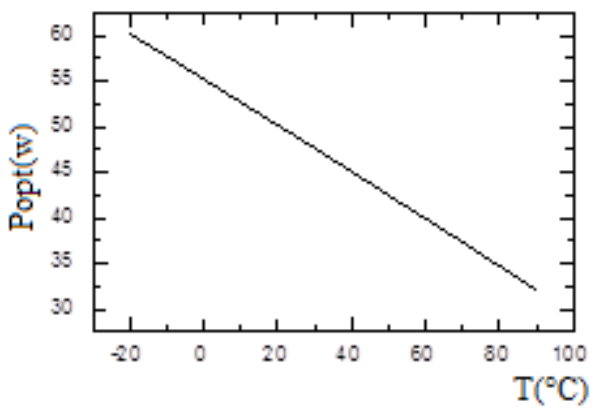

b- under varied temperature, Es $=100 \%$

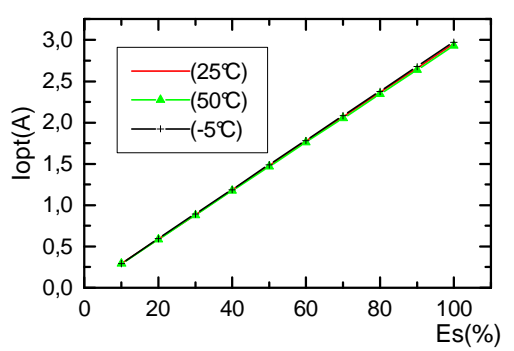

c- Iopt versus Es for different $\mathrm{T}$

Fig. 6. Characteristics curves under varied Es and under varied T

\section{Maximum Power Transfer}

There are three factors that mainly affect the performance of PV system; insulation, temperature and electric load. There is no control over Es and T. In order to operate the PV array at its MPP, the PV system must contain a maximum power point tracking (MPPT) controller. By controlling the switching of this converter, the power control can be provided. For the equivalent circuit shown in Figure 7, the maximum power transfer can be done by adjusting K : DC-DC converter duty cycle. The control technique the most used consist to act on the duty cycle automatically to place the generator at its optimal value whatever the variations of insulation, temperature or sudden changes in loads The DC-DC converter is called MPPT: maximum power point tracker. The converter must at all times track the maximum power point [4-7].

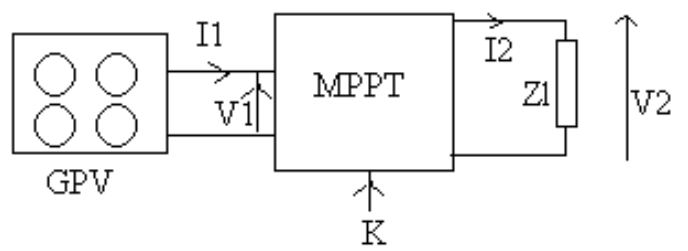

a- MPPT control

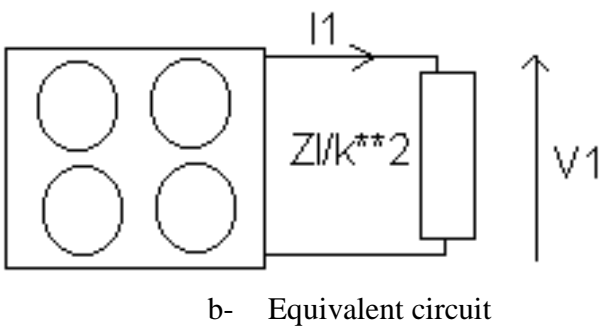

Fig. 7. MPPT principle

$$
\begin{aligned}
& V_{2}=K \cdot V_{1} \\
& I_{2}=K^{-1} \cdot I_{1} \\
& P_{2}=P_{1} \\
& Z_{e}=K^{-2} \cdot Z_{l}
\end{aligned}
$$

For

$$
K=K_{o p t} \quad V_{1}=V_{o p t} \& I_{1}=I_{o p t}
$$

To verify this method, an experimental bench has been realized as shown in Figure 8.

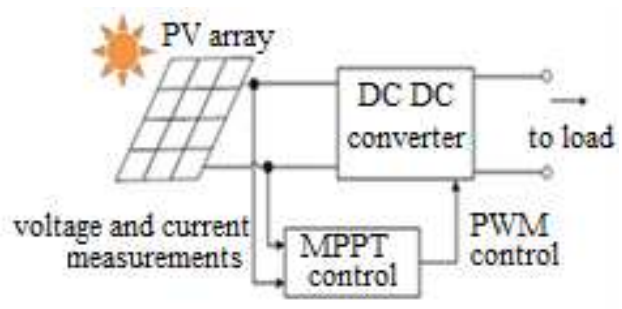

Fig. 8. Experimental bench

The control module has been implemented on a microcontroller [2-4]. All practical results below consider a PVA consists of three modules in series.

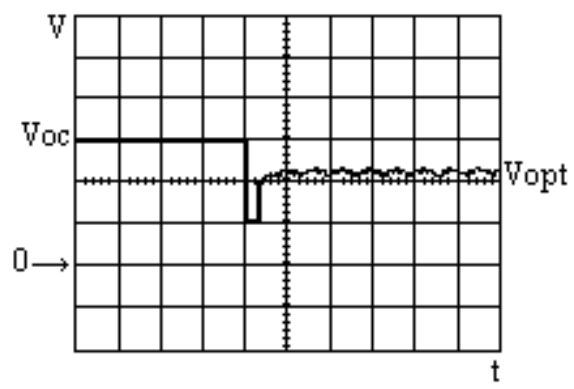

a- Voltage variations

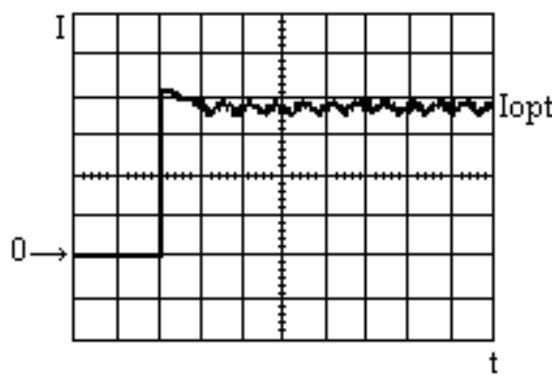

b- Current variations

Fig. 9. Starting PVA voltage and current characteristics 
Figure (9) shows PVA voltage and current experimental curves. Initially, the voltage $\mathrm{Voc}$ is $60 \mathrm{~V}$ which corresponds to zero current . The connected load has an operating point of a voltage of about $21 \mathrm{~V}$ and a current of about 2.05A. The MPP operation must be recovered. As seen in the figures, the operating point reached the optimum power with optimal voltage of $45 \mathrm{~V}$ and an optimal current approximately equal to $1.7 \mathrm{~A}$.

Figure (10) illustrates the the power $\mathrm{P}$ as a function of the voltage practical results. The search of MPP gradually is shown. 'A ' is the operating point with voltage VA, current IA , power PA. According to the power's comparison algorithm [2]-[4], the developed program compares powers and gradually adjusts $\mathrm{K}$ to move towards the MPP. At MPP, power is Popt with Vopt . The operating system will stabilize at the end between three points encircling the MPP .

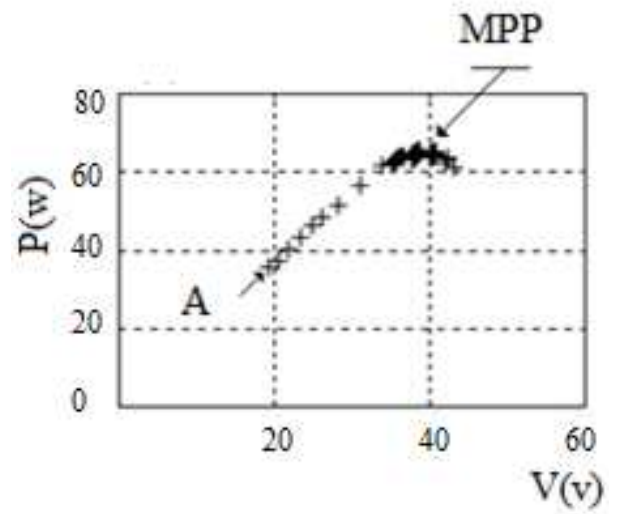

Fig. 10. MPP Gradual Research

Sudden load changes case have been verified practically. Figure (11-a) and (11-b) show experimental results. For example at point $\mathrm{A}$, there has been sudden decrease in load (Figure 11-a). Figure (11-b) shows the case where a sudden increase in load occurred at point A. We see in Figures that the system find always an optimal operation.

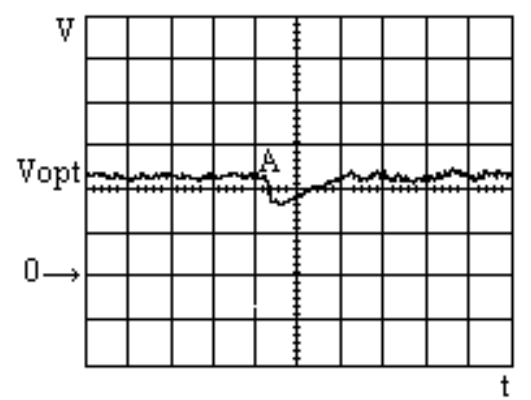

a) Behavior of PVA voltage at load decrease

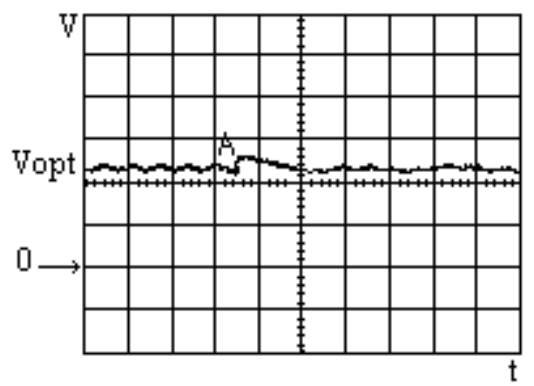

b) behavior of the PVA voltage at load increase Fig. 11. Practical results

\section{Electrical PV Array Reconfiguration Strategy}

This section presents a novel strategy for producing the best power output from photovoltaic arrays using dynamic cell reconfiguration. We propose a new and efficient system for the maximization of the power output generated by the PV system. A suitable reconfiguration of the modules is adopted [8]-[12].

For illustration purposes, we select two configurations.

On Figure 12, the PVA characteristics for two different configurations $\left(\mathrm{N}_{\mathrm{p}} \times \mathrm{N}_{\mathrm{s}}=2 \times 3\right.$ and $\left.1 \times 6\right)$ as well as that of two different loads $\mathrm{Za}$ and $\mathrm{Zb}$ are plotted. In this case, the insulation and temperature are kept constant. As it could be seen the power corresponding to point $A_{1}$ is higher than that of point $A_{2}$, which means that the first configuration $(2 \times 3)$ provides a better load matching for this load than the second configuration (1x6). Whereas for load $\mathrm{Zb}$, the power on point $\mathrm{B}_{1}$ is higher than that of point $\mathrm{B}_{2}$, which means that in this case, the second configuration is better. It is then necessary to select on line and in real time the PVA appropriate configuration for a given load and under given working conditions in order to reduce the mismatch losses [3], [10]-[12].

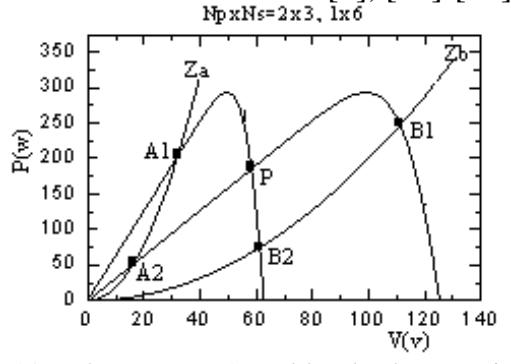

Fig. 12. The P-V PVA and loads characteristics

The Figure 12 shows that the two P-V, PVA characteristics intersect on a point noted ' $\mathrm{P}$ '. On this operating point, either configuration could be used. Point ' $\mathrm{P}$ ' is taken as a reference. For loads where their operating points are at the point ' $\mathrm{P}$ ' left, configuration 1 (noted parallel configuration) should be used. And for all loads with operating points situated at the point ' $\mathrm{P}$ ' right, configuration 2 (noted series configuration) is to be used. Therefore it is necessary to find a way to determine on line the point's ' $P$ ' position: the voltage Vcom and the current Icom corresponding to this point. Then, the load voltage and current is compared to Vcom and Icom. The PVA is switches then onto the appropriate configuration [3] [10]-[12].

The commutation current varies linearly with insulation and is hardly affected by the temperature. Therefore it could be described by the following equation:

$$
\text { Icom }=K^{\prime} \text {.Es }
$$

Where, $\mathrm{K}^{\prime}$ is a constant which depends upon of the module's number in parallel and types.

Vcom as a function of insulation for different temperatures has characteristics which have been subdivided into 2 intervals and a linear 
approximation has been used in each interval. Vcom will then be described by the following equation [3], [10]-[12]:

$$
V c o m=\alpha_{i} \cdot E s+\beta_{i}
$$

Where $\alpha \mathrm{i}, \beta \mathrm{i}$ are constants relative to each interval and calculated at $25^{\circ} \mathrm{C}$. Vcom is significantly affected by the temperature [3],[10-12]. As $\mathrm{T}$ increases, Vcom diminishes linearly. To take into account the temperature's effect, the equation is corrected and rewritten as follows:

$$
V \operatorname{com}=\alpha_{i} \cdot E s+\beta_{i}+\delta_{i}(25-T)
$$

where $\delta \mathrm{i}$ is a constant.

To test the validity of the method, an experimental system has been considered ([3],[10-12]) and is illustrated in Figure 13. The control card permits the insulation and the temperature measurements, to determine Vcom, Icom. If the PVA is in the parallel configuration then the current flowing into the load is measured and compared to Icom. If it is higher, the PVA remains in its actual configuration, otherwise it is reconfigured into the series configuration. If however the PVA is in the series configuration, then the load's voltage is measured and compared to Vcom. If it is greater, then the PVA remains in its actual configuration, otherwise it is switched onto the parallel configuration. As a result the PVA is always switched onto its best configuration for any load and any weather conditions on line.

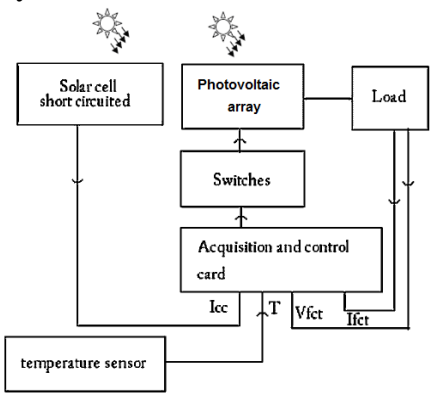

Fig. 13. Experimental system bloc scheme

Figure 14 shows experimental results obtained with the described system. A variable load has been used in order to cover a large currents and voltages range. As it could be seen the commutation from one configuration to the other occurs exactly on the same predicted point ' $\mathrm{P}$ ' noted Pcom in figure below [3],[10]-[12].

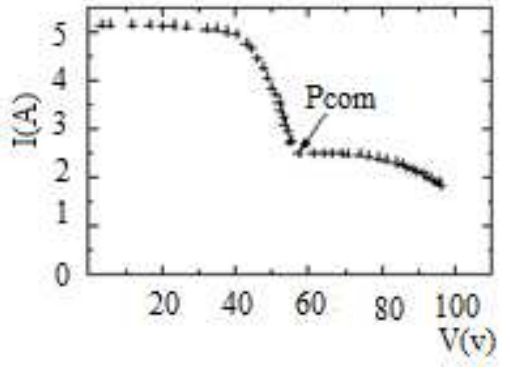

Fig. 14. Practical I-V results at Es $=78 \%, T=27^{\circ} \mathrm{C}$.

\section{Mismatching problem}

PV system can be subjected to partial shading. Our simulation (Figure 15) treated the case of 3 PV modules [13]-[14].

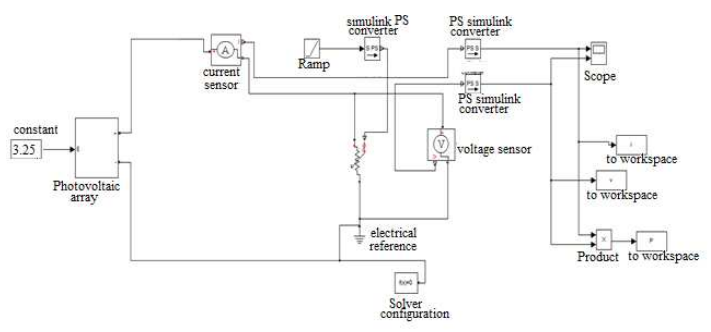

Fig. 15. Bloc diagram of model

Figure (16) shows this case [13]. We simulated a sudden shading $50 \%, 20 \%$ after an irradiance of $100 \%$. Figure 17-a shows the power-voltage curve obtained with the addition of a bypass diode for each module. Figure 17-b illustrates characteristic obtained without these diodes.

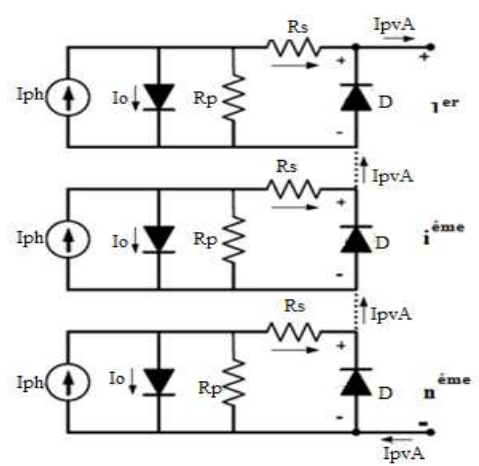

Fig. 16. Modules with by pass diodes

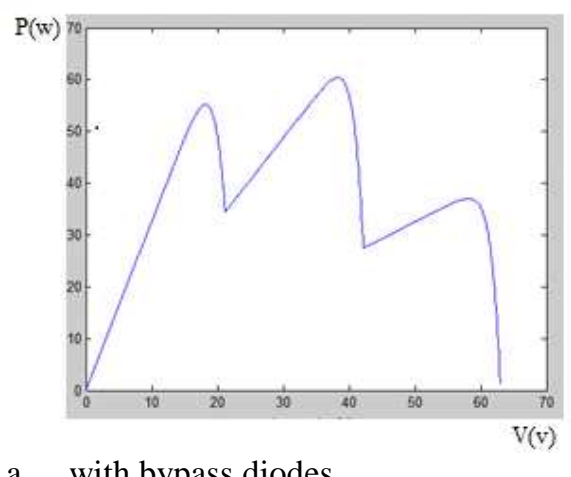

a. with bypass diodes 


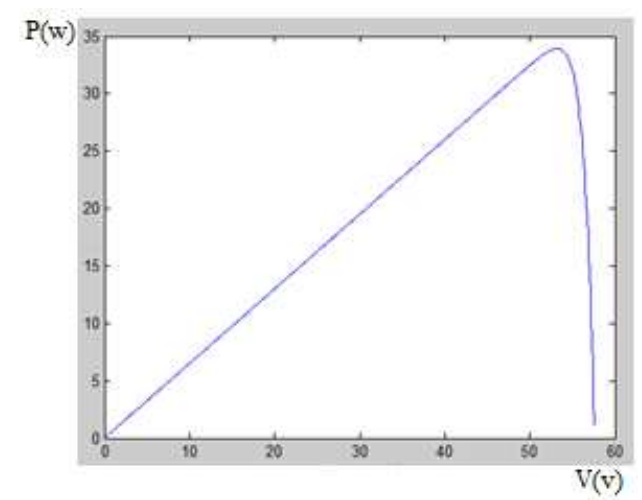

b. without bypass diodes

Fig. 17. photovoltaic generator P-V curves in partial shade.

$\mathrm{P}-\mathrm{V}$ curves exhibit multiple peaks in Figure 17-a. In Figure 17-b, there is one peak corresponding to optimum power with a low value.

\section{References}

[1] G. Makrides, B. Zinsse, M. Schubert and al., "Energy yield prediction errors and uncertainties of different photovoltaic models", Progress in photovoltaics 2013, Vol. 21, No. 4, pp. 500-516.

[2] FZ. Zerhouni, M. Zegrar, MT. Benmessaoud and A. Boudghene stambouli: "Improvement of green clean energy system's operation", Journal of electrical system 2009, Vol. 5, juin 2009, pp. 6-26.

[3] F. Z Zerhouni, M. H Zerhouni, M. Zegrar, A Boudghene Stambouli, Study of hybrid sustainable energy system based on pem fuel cells and photovoltaic-module power generator, chapter's book, Source title: Sustainable ICTs and Management Systems for Green Computing, IGI global, USA 2012, DOI: 10.4018/978-1-4666-1839-8.ch018, ISBN13: 9781466618398, ISBN10: 1466618396, EISBN13: 9781466618404, pp. 399-422.

[4] FZ. Zerhouni, MH. Zerhouni, M. Zegrar and al.: "Proposed methods to increase the output efficiency of a photovoltaic (pv) system", Acta polytechnica hungarica 2010, Vol. 7, No. 2, pp. 55-70.

[5] S. Dezso, M. Laszlo, K. Tamas and al, "on the perturband-observe and incremental conductance mppt methods for pv systems", IEEE journal of photovoltaics 2013, Vol. 3, No. 3, pp. 1070-1078.

\section{Conclusion}

Maximum power point tracker method has been implemented, in real time. PV-load coupling system should be able to maximize the energy output of the PV generator, which should operate always at its maximum power point (MPP) in order to achieve maximum global efficiency. The second method is based on the determination of the optimal configuration of a PV generator for a fixed number of modules. The proposed methods have been validated by the experimental data whatever are climatic or load conditions. The quality of PV-load matching will be improved. These methods are simple to implement.
\end{abstract}

[13] SM. Mohammadmehdi, R. Rahmani, R. Yusof and A.E.T. Renani, "Analytical Modeling of Partially Shaded Photovoltaic Systems", Energies 2011, Vol. 6, pp. 128-144.

[14] I. Kashif and S. Zainal: "A deterministic particle swarm optimization maximum power point tracker for photovoltaic system under partial shading condition", IEEE transactions on industrial electronics 2013, Vol. 60, No. 8, pp. 3195-3206. FZ. Zerhouni, M. Zegrar, MT. Benmessaoud, M.H energy reviews 2013, Vol. 23, pp. 224-241.
KM. Tsang and WL. Chan, "Model based rapid systems", Energy conversion and management 2013, Vol. 70, pp. 83-89. Photovoltaic Energy 1990, Vol. 44, 1990, pp 51-55.

ZM. Salameh and L. Chaozi, "Optimum switching points for array reconfiguration controller". 21st IEEE Photovoltaic Conference 1990, vol 2, Kissimee, FL, U.S.A., pp 971-976. 24, $\mathrm{N}^{\circ} 11$, pp 6126-6130.

FZ. Zerhouni, M. Zegrar, MT. Benmessaoud, A. Boudghene Stambouli and A. Midoun, "A novel method to optimize photovoltaic generator operation", International Journal of Energy Research 2008, Vol. 32, N${ }^{\circ}$, pp $1444-1453$.

Boudghene Stambouli and of a novel strategy to improve the operation of an environmentally friendly energy system based upon photovoltaics and fuel cells", Journal of Arab universities for basic and applied sciences 2008, universities for Zerhouni and A. Stambouli Boudghene, "Optimum load matching by an array reconfiguration in
photovoltaic generators", Energy Fuels 2010, Vol.

(n)

